\title{
Oral Care Needs of the Elderly: A Growing Challenge
}

\author{
James L Ratcliff* \\ Rowpar Pharmaceuticals, Inc, USA \\ Received: April 25, 2018; Published: May 30, 2018 \\ *Corresponding author: James L Ratcliff, Rowpar Pharmaceuticals, Inc., 16100 N. Greenway-Hayden Loop, Suite 400, Scottsdale, AZ 85260, USA
}

\section{Opinion}

Populations are aging throughout the world. As people age, their need for regular professional oral care and for home oral hygiene increases. Oral diseases have been linked to the increased incidence of certain systemic diseases and early mortality. Yet, the provision for satisfactory oral care for the elderly is often lacking. This essay reviews the oral care needs of the elderly, the challenges in providing such care to seniors that are home-bound or living in assisted care facilities, and notes certain opportunities for raising the standards of care. Greater understanding of the oral healthcare needs of elderly in assisted care facilities is needed. Populations in many places across the globe - China, Japan, the United States and the United Kingdom, to name a few -- are aging rapidly, increasing the need for oral care in long term care facilities. These elderly have specific daily oral hygiene needs as well as the need for regular professional care. For example, over 12 percent of the current U.S. population is 65 or older and within a dozen years, one in five adults 65 or older [1]. Today, more than 1.5 million Americans live in assisted care facilities, and the number of adults requiring assisted care is likely double by $2050[2,3]$.

Many elderly living at home turn to community health centers for their healthcare needs, including oral care. Yet, there is wide disparity in standards of care and quality of services provided to the elderly at these centers [4]. Elderly also turn to dental clinics for their oral care. A study of clinics in the state of Michigan showed that only $7 \%$ of seniors with a high risk of dental caries received a fluoride treatment, and none of those offered the treatment refused [5]. Home healthcare providers report that most adults would prefer to remain in their own home, and for those individuals, home health care is provided by a variety of caregivers, including traveling nurses and nursing assistants, physical therapists, dental hygienists and dental assistants. These seniors require help in daily activities, including personal and oral hygiene, dressing, taking medications, and eating [6].

Thanks to advances in dentistry, including the provision of anti-caries oral care products and regular professional care, these seniors have more of their natural teeth increasing the need for regular dental hygiene care and regular home oral care practices. Biofilms that adhere to teeth are not naturally removed by the body and therefore must be removed physically or degraded by the use of properly selected oral care products and by regular dental care [7]. Often such care is not regularly provided by the assisted care facilities, is an option that the person overseeing the care of the senior may not be aware of, and the expense of oral care for seniors in nursing facilities or receiving in-home care assistance may not be covered by certain insurance plans. Many seniors in assisted care facilities receive reduced or no access to professional dental services at the very time when they have physical or mental challenges to maintaining effective daily home oral hygiene $[8,9]$. While dental services and home oral hygiene may be regarded as optional, its absence can increase the risk of general systemic diseases and of the quality and longevity of life of the elderly.

The incidence of aspiration pneumonia predicts death in assisted care facilities [10]. It also a primary reason why elderly in assisted care facilities require hospitalization. Daily oral hygiene for the elderly in assisted care or hospitals decreases the risk of aspiration pneumonia [11]. Twice daily oral care with an antimicrobial oral rinse can reduce the likelihood of pneumonia infection and contagion, reaping benefits not only for the elderly residents, but also for the assisted care facility and the hospital, who may be financially penalized for re-admissions. The elderly are prone to mucositis. For example, in one study almost half $(48 \%)$ of the geriatric patients examined had one or more oral mucosal lesions. Over 25 different oral mucosal conditions were found, including lingual varices $(13.68 \%)$, denture induced inflammatory fibrous hyperplasia $(4.21 \%)$, and squamous cell carcinoma (4.21\%). The incidence of mucosal lesions increases as the patient ages, the oral mucosa becoming more vulnerable to noxious substances and external carcinogens [12]

While the oral care needs of the seniors are likely to increase with age, sadly they are less likely to receive regular dental care and 
are less likely to complete treatment plans developed during dental visits. Researchers conducted a 16 month retrospective study of 187 patients receiving treatment at a university-based dental clinic showing a high prevalence of incomplete planned treatments (87.4\%) among seniors. Periodic compliance audits of treatment plans devised for elderly patients may improve oral healthcare [13]. The elderly are often taking several medications, which singularly or in combination may have negative effects on their oral health. For example, seniors may experience dry mouth (xerostomia) as a result of mouth-breathing or medications. While they may report eating regularly, they may experience decreased ability to chew, swallow and digest foods. The twin challenges of adult dental caries and periodontal disease are of growing prevalence among seniors [14]. Oral care products designed specifically for these needs of the elderly should be selected. Yet, regular professional dental care is overlooked by assisted care providers, despite that assisted care facilities receiving Medicaid and Medicare insurance payments are required to provide daily oral hygiene [15-17].

Often, the caregiver staff have the responsibility for providing daily oral hygiene in assisted care facilities; nurses often perform oral care for homebound seniors; their training in oral care may vary greatly $[18,19]$. In-service training for caregiver staff in conducting oral assessments and in providing daily oral care can improve the health outcomes of the residents $[19,20]$. Caregivers need to know selecting a soft toothbrush with a small head will be more effective with elderly who have sensitive mouths and who must rely on others to assist with their oral care. Caregivers also need to know that the life span of a toothbrush is 3-4 weeks. Inadvertently shared toothbrushes among assisted care facilities residents is a primary means for the transmission and contagion of diseases, such pneumonia. Toothbrushes need to be stored not only to prevent inadvertent sharing but also to limit the growth of bacteria and mold.

Finally, it should be noted that caregivers are typically not the persons who purchase oral care products for home-bound seniors and elderly in assisted care facilities. The person responsible for the care of the home bound elderly needs to be told about needed dental supplies. Purchases of oral care products may be made by a purchasing director who may not even be present at particular assisted-care facilities, particularly when the facility is managed in a larger group or corporate environment. Purchasing agents need to be aware that oral care products should not be purchased by cost considerations alone. Patients who refuse oral care because the mouth rinse stings or burns their mouth or stains their teeth are more susceptible to systemic diseases and infection due to non-compliance. Patients may refuse oral care because the toothpaste brings on oral sores, or is painful to use due to oral sores engendered by the medications they are taking. Dental health professions need to become effective advocates for providing seniors with the same quality oral care they expect for the patients they regularly see. We need to advance the standard of care for the elderly to that we expect for the general population, to help them get well and stay well, and to help them enjoy a quality of life throughout their remaining years.

\section{References}

1. (2010) US Census Bureau 2010, The Next Four Decades: The Older Population in the United States: 2010 to 2050.

2. Jones AL, Dwyer LL, Bercovitz AR, Strahan GW (2009) The National Nursing Home Survey: 2004 overview. Vital Health Stat 167: 1-155.

3. (2003) US Department of Health and Human Services 2003, The Future Supply of Long Term Care Workers in Relation to the Aging Baby Boom Generation.

4. Marina A, Demopoulos C (2016) Racial and ethnic oral health disparities among patients in community-based programs in the greater Las Vegas area, Poster Session 1277, American Association for Dental Research, Annual Meeting, Los Angeles, USA.

5. Yang Y, Karl E, Fontana M, de Peralta TL (2016) One-Year Analysis of High Caries Risk Patient Management, Poster Session 1896, American Association for Dental Research, Annual Meeting, Los Angeles, USA.

6. Forsell M, Sjogren P, Johansson O (2009) Need of assistance with daily oral hygiene measures among nursing home resident elderly versus the actual assistance received from the staff. Open Dent J 3: 241-244.

7. Corbin A, Betsey Pitts, Albert Parker, Philip S. Stewart (2011) Antimicrobial penetration and efficacy in an in vitro oral biofilm model. Antimicrobial Agents and Chemotherapy 55(7): 3338-3344.

8. Walgama K (2016) A state-level analysis of policies impacting dentistry in long-term-care facilities, Poster Session 690, American Association for Dental Research, Annual Meeting, Los Angeles, USA.

9. Branson B, Simmer-Beck M (2013) Addressing the oral health needs of long term care facility residents. Dimensions of Dental Hygiene 11(8): 31-35.

10. Mehr DR, Zweig SC, Kruse RL (1998) Mortality from lower respiratory infection in nursing home residents. A pilot prospective communitybased study. J Fam Pract 47: 298-304.

11. Sjogren P, Nilsson E, Forsell M, Johansson O, Hoogstraate J (2008) A systematic review of preventive effect of oral hygiene on pneumonia and respiratory infections in elderly people in hospitals and nursing homes: effect estimates and methodological quality of randomized controlled trials. J Am Geriatr Soc 56: 2124-2130.

12. Shet R, Shetty SR, MK, Kumar MN, Yadav RD, et al. (2013) A study to evaluate the frequency and association of various mucosal conditions among geriatric patients. Journal of Contemporary Dental Practice 14(5): 904-910.

13. Hawas H, Lim J, Awad MA, Feine J (2016) Oral Healthcare Management and Provision: A Mixed Methods Study, Poster Session 529, American Association for Dental Research, Annual Meeting, Los Angeles, USA.

14. Johnson VB (2012) Evidence-based practice guidelines: oral hygiene care for functionally dependent and cognitively impaired older adults. J Gerontol Nurs 38: 11-19.

15. Coleman P, Watson NM (2006) Oral care provided by certified nursing assistants in nursing homes. J Am Geriatr Soc 54: 138-143.

16. Wardh I, Andersson L, Sorensen S (1997) Staff attitudes to oral health care. A comparative study of registered nurses, nursing assistants and home care aides. Gerodontology 14: 28-32.

17. Cornell University Law School (2016) Legal Information Institute. 42 CFR 483.25 - Quality of care.

18. Boyle S (1992) Assessing mouth care. Nurs Times 88: 44-46.

19. Jablonski R, Munro CL, Grap MJ, Schubert CM, Ligon M, Spigelmyer P (2009) Mouth care in nursing homes: knowledge, beliefs, and practices of nursing assistants. Geriatr Nurs 30: 99-107.

20. Kullberg E, Forsell M, Wedel P, Johansson O (2009) Dental hygiene education for nursing staff. Geriatr Nurs 30: 329-333. 
(C) (P) This work is licensed under Creative Submission Link: https://biomedres.us/submit-manuscript.php

Assets of Publishing with us
BIOMEDICAL
RESEARCHES

